\title{
Milk and dairy consumption and risk of cardiovascular diseases and all-cause mortality: dose-response meta-analysis of prospective cohort studies
}

\author{
Jing Guo ${ }^{1}$ - Arne Astrup ${ }^{2} \cdot$ Julie A. Lovegrove $^{3} \cdot$ Lieke Gijsbers $^{4} \cdot$ David I. Givens $^{1}$ • \\ Sabita S. Soedamah-Muthu ${ }^{4}$
}

Received: 6 October 2016/Accepted: 27 March 2017/Published online: 3 April 2017

(c) The Author(s) 2017. This article is an open access publication

\begin{abstract}
With a growing number of prospective cohort studies, an updated dose-response meta-analysis of milk and dairy products with all-cause mortality, coronary heart disease (CHD) or cardiovascular disease (CVD) have been conducted. PubMed, Embase and Scopus were searched for articles published up to September 2016. Random-effect meta-analyses with summarised dose-response data were performed for total (high-fat/low-fat) dairy, milk,
\end{abstract}

Electronic supplementary material The online version of this article (doi:10.1007/s10654-017-0243-1) contains supplementary material, which is available to authorized users.

Jing Guo

jing.guo@pgr.reading.ac.uk

Arne Astrup

ast@nexs.ku.dk

Julie A. Lovegrove

j.a.lovegrove@ reading.ac.uk

Lieke Gijsbers

lieke.gijsbers@wur.nl

David I. Givens

d.i.givens@ reading.ac.uk

Sabita S. Soedamah-Muthu

sabita.soedamah-muthu@wur.nl

1 Institute for Food, Nutrition and Health, University of Reading, Reading RG6 6AR, UK

2 Department of Nutrition, Exercise and Sports, University of Copenhagen, 2200 Copenhagen, Denmark

3 Hugh Sinclair Unit of Human Nutrition, Institute for Cardiovascular and Metabolic Research, University of Reading, Reading RG6 6AP, UK

4 Division of Human Nutrition, Wageningen University and Research, 6708 WE Wageningen, The Netherlands fermented dairy, cheese and yogurt. Non-linear associations were investigated using the spine models and heterogeneity by subgroup analyses. A total of 29 cohort studies were available for meta-analysis, with 938,465 participants and 93,158 mortality, 28,419 CHD and 25,416 CVD cases. No associations were found for total (high-fat/ low-fat) dairy, and milk with the health outcomes of mortality, CHD or CVD. Inverse associations were found between total fermented dairy (included sour milk products, cheese or yogurt; per $20 \mathrm{~g} /$ day) with mortality (RR $0.98,95 \%$ CI $\left.0.97-0.99 ; \mathrm{I}^{2}=94.4 \%\right)$ and CVD risk (RR $0.98,95 \%$ CI $0.97-0.99 ; \mathrm{I}^{2}=87.5 \%$ ). Further analyses of individual fermented dairy of cheese and yogurt showed cheese to have a $2 \%$ lower risk of CVD (RR $0.98,95 \%$ CI $0.95-1.00 ; \mathrm{I}^{2}=82.6 \%$ ) per $10 \mathrm{~g} / \mathrm{day}$, but not yogurt. All of these marginally inverse associations of totally fermented dairy and cheese were attenuated in sensitivity analyses by removing one large Swedish study. This meta-analysis combining data from 29 prospective cohort studies demonstrated neutral associations between dairy products and cardiovascular and all-cause mortality. For future studies it is important to investigate in more detail how dairy products can be replaced by other foods.

Keywords Dairy · Milk · Fermented dairy - All-cause mortality $\cdot$ Cardiovascular disease $\cdot$ Dose-response metaanalysis

\section{Introduction}

Cardiovascular disease (CVD) is the leading cause of mortality and disability worldwide [1]. Together with smoking, obesity and inactivity, diet is considered to be one of the most important prevention strategies for CVD 
[2]. Milk and dairy foods have been recommended in most dietary guidelines around the world, but the association of milk or dairy food consumption with CVD is still controversial [3, 4]. An earlier meta-analysis [5] which included 17 prospective cohort studies showed that milk intake was not associated with total mortality or CHD mortality, but there was a borderline significant inverse association with CVD mortality based on limited studies. There were not enough data to examine the effects of other dairy products or milk fat content. Since then, further prospective cohort studies have been published. For example, one recent Swedish publication with two large Swedish cohorts [6] reported that higher milk consumption was associated with a doubling of mortality risk including CVD mortality in the cohort of women. Since this paper was published in 2014, there has been mounting debate from different researchers regarding its seemingly contradictory results $[7,8]$. This has caused new uncertainty about the effects of milk and dairy intake on human health. Recently, new meta-analyses of dairy consumption and risk of stroke [9], butter and risk of CVD, diabetes and mortality [10] have been published, showing predominantly neutral or marginally beneficial associations for all dairy products. Therefore, we conducted a comprehensive dose-response meta-analysis to examine linear and non-linear associations between milk and dairy products with all-cause mortality, CHD and CVD events using existing prospective cohort studies of adequate quality.

\section{Methods}

\section{Literature search and study selection}

This review was conducted based on guidelines of Metaanalysis of Observational Studies in Epidemiology [11]. Prospective cohort studies published up to Sep 2016 (without language restriction) were searched using PubMed, Embase, and Scopus database, the query syntax of searching is shown in the Supplemental Methods (see search strategy). After excluding duplicates and based on titles and abstracts, we excluded studies on animals, baseline age $\leq 18$ years, or populations with prior CVD, diabetes, or any other chronic diseases. Eligible studies were selected by using predefined inclusion criteria of prospective cohort studies, healthy populations and original articles on the association of milk and dairy intake and allcause mortality, CHD or CVD. In addition, supplementary hand searching of reference lists of previous reviews or meta-analyses was conducted. Of 59 eligible full articles, 29 articles [6, 12-39] met the inclusion criteria (see Fig. 1). Several authors or coworkers provided additional data for this meta-analysis $[14,16,19,23,27,28,32,34,37,40]$.

\section{Data extraction and quality assessment}

Data were extracted from published articles by using a structured extraction form, which included descriptive characteristics of the study, range of intake, median intake, number of participants, number of mortalities, CHD or CVD cases, person-years at risk, and relative risk (RR) with $95 \%$ CI for each unit of dairy intake. For studies that reported results from different multivariable-adjusted models, the model with the most confounding factors was extracted for the meta-analysis. If dairy intake was presented in servings or times per period of time [12-20, 22, 23, 34-36, 39], we converted the portion size into grams per day by using standard units of $244 \mathrm{~g}$ for milk (585 g for 1 pint of milk); $244 \mathrm{~g}$ for yoghurt and $40 \mathrm{~g}$ for cheese [41, 42]. One serving of total dairy, high-fat dairy and low-fat dairy was taken to be $200 \mathrm{~g}$, similar to our previous meta-analysis [5]. When studies reported country specific conversion factors, these were used to calculate intake as g/day [26, 29, 30].

In some studies the mean intakes of dairy categories were not reported, in which case we calculated the mean value by using the lower and upper limit. For open-ended upper limits of intake, the same range as the lower category was applied. The categories of dairy types were defined in accordance with the definition in the original articles (Supplemental Table 2).

Two independent reviewers determined the quality of the 29 studies based on the Newcastle-Ottawa quality assessment scale (NOS, Supplemental Methods) [43]. By evaluation of selection, comparability and outcome, the rating system scores studies from 0 (highest degree of bias) to 9 (lowest degree of bias). Additionally we investigated the funding sources of all of the eligible studies. The four categories of funding were recorded as industry, partial funded by industry, research institution and unknown.

\section{Statistical analysis}

Meta-analyses of each dairy type were performed if the number of studies was three or more. Splined variables were generated by MKSPLINE in STATA version 13.0 to determine the most appropriate knot points of nonlinear associations from goodness-of-fit tests and Chi square statistics. Spine analysis and dose-response generalised least-square trend (GLST) meta-analysis were applied for the further analysis of linear or nonlinear associations. Incremental dose-response RRs were derived from the random-effects meta-regression trend estimation of summarised dose-response data. Ding's spaghetti plot was used to present the shapes of the association within individual studies, as described previously [44]. Forest plots were created to assess the linear dose-response slopes and 


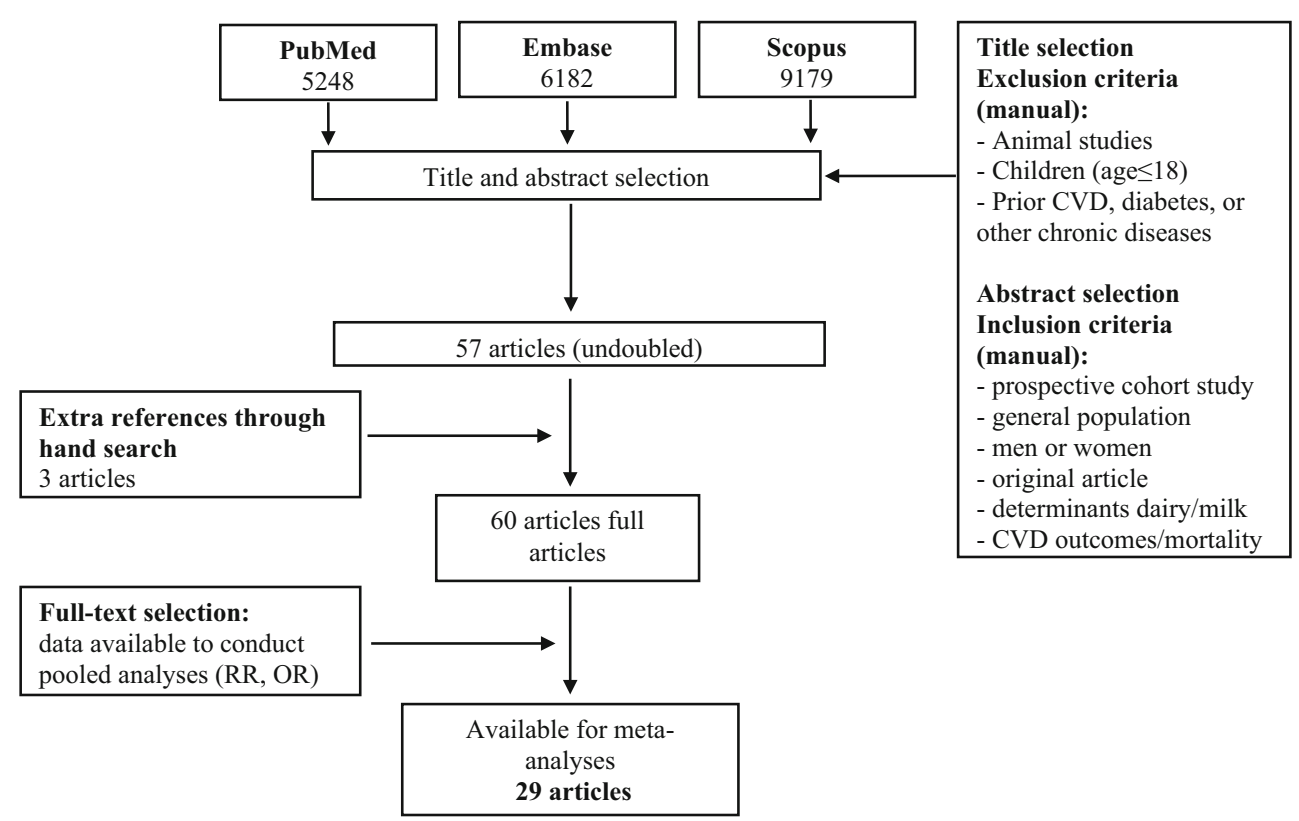

Fig. 1 Flowchart of meta-analysis on dairy consumption and incident CVD, CVD mortality and all-cause mortality

corresponding $95 \% \mathrm{CI}$ across relative studies with increments of $200 \mathrm{~g} / \mathrm{day}$ for total, high-fat, and low-fat dairy; $244 \mathrm{~g} /$ day for milk; $20 \mathrm{~g} /$ day for total fermented dairy (includes cheese, yogurt and soured milk products); $10 \mathrm{~g} /$ day for cheese; $50 \mathrm{~g} /$ day for yogurt. Sensitivity analysis was based on linear dose-response slopes by excluding one study population at a time.

To explore heterogeneity between studies, I-squared was calculated from Cochrane $\mathrm{Q}$ test [45]. In addition, subgroup analyses were performed providing that at least 6 study populations were available by age $(\leq 50$ years, $>50$ years), follow-up duration ( $\leq 10$ years, $>10$ years), gender (men, women, both men and women), continent, confounding factors (whether analyses were or were not adjusted for the following 7 confounders age, sex, smoking, alcohol, body mass index (BMI), physical activity, food energy intake), BMI $\left(\leq 25 \mathrm{~kg} / \mathrm{m}^{2},>25 \mathrm{~kg} / \mathrm{m}^{2}\right)$ and Newcastle-Ottawa quality score $<$ or $\geq 7$. When number of the examined studies $\geq 10$, potential publication bias was assessed by means of the Eggers test [46] and symmetry of the funnel plot. All of the statistical analyses were performed in STATA version 13.0 (StataCorp. College Station, Texas, USA). Two-sided $P$ values $<0.05$ were considered as statistically significant.

\section{Results}

Overviews of key characteristics of the 29 prospective cohort studies are shown in Table 1. The included participants of each dairy exposure data on all-cause mortality, CHD or CVD are presented in Table 2. A total of 783,989 participants, 93,158 mortality cases, 28,419 CHD and 25,416 CVD were included in the analysis. There were 3 studies conducted in Asia (Japan and Taiwan) [28, 35, 39], 2 studies in Australia [24, 29], 7 in the United States $[12,14-16,19,22,34]$ and the remaining 17 studies in Europe. A total of 6 studies presented sex-specific results, 3 studies were in men [18-20] and 3 in women [15, 16, 30]. There was one study [12] with missing data on age and 4 studies with missing BMI data [12, 21, 33, 36]. The estimated mean age was 57 years (range 34-80 years) and mean value of BMI was $25.4 \mathrm{~kg} / \mathrm{m}^{2}$ (range $22.3-27.1 \mathrm{~kg}$ / $\mathrm{m}^{2}$ ). The duration of follow-up ranged from 5 to 25 years, with a mean follow-up of 13 years. Study characteristics of each dairy intake category by outcomes are shown in Table 2. Results of quality assessment are shown in the Supplemental Table 1, with 18 studies scoring $\geq 7$. All of the studies were funded by a research institute except one study [13] without funding information, thus sub-group analysis was not conducted by funding source. There was no evidence of publication bias in the meta-analyses of milk or dairy consumption with different health outcomes (Supplemental Figs. 19-27).

\section{Total, high-fat, and low-fat dairy}

Total dairy intake (per $200 \mathrm{~g} /$ day) was not associated with the risk of all-cause mortality (Supplemental Figure 1; RR $0.99,95 \%$ CI $0.96-1.03,10$ populations), CHD (Supplemental Figure 2; RR 0.99, 95\% CI 0.96-1.02, 12 populations) or CVD (Supplemental Figure 3; RR 0.97, 95\% CI 0.91-1.02). Considerable heterogeneity was observed in the meta-analyses of mortality $\left(\mathrm{I}^{2}=62.2 \%\right.$, 


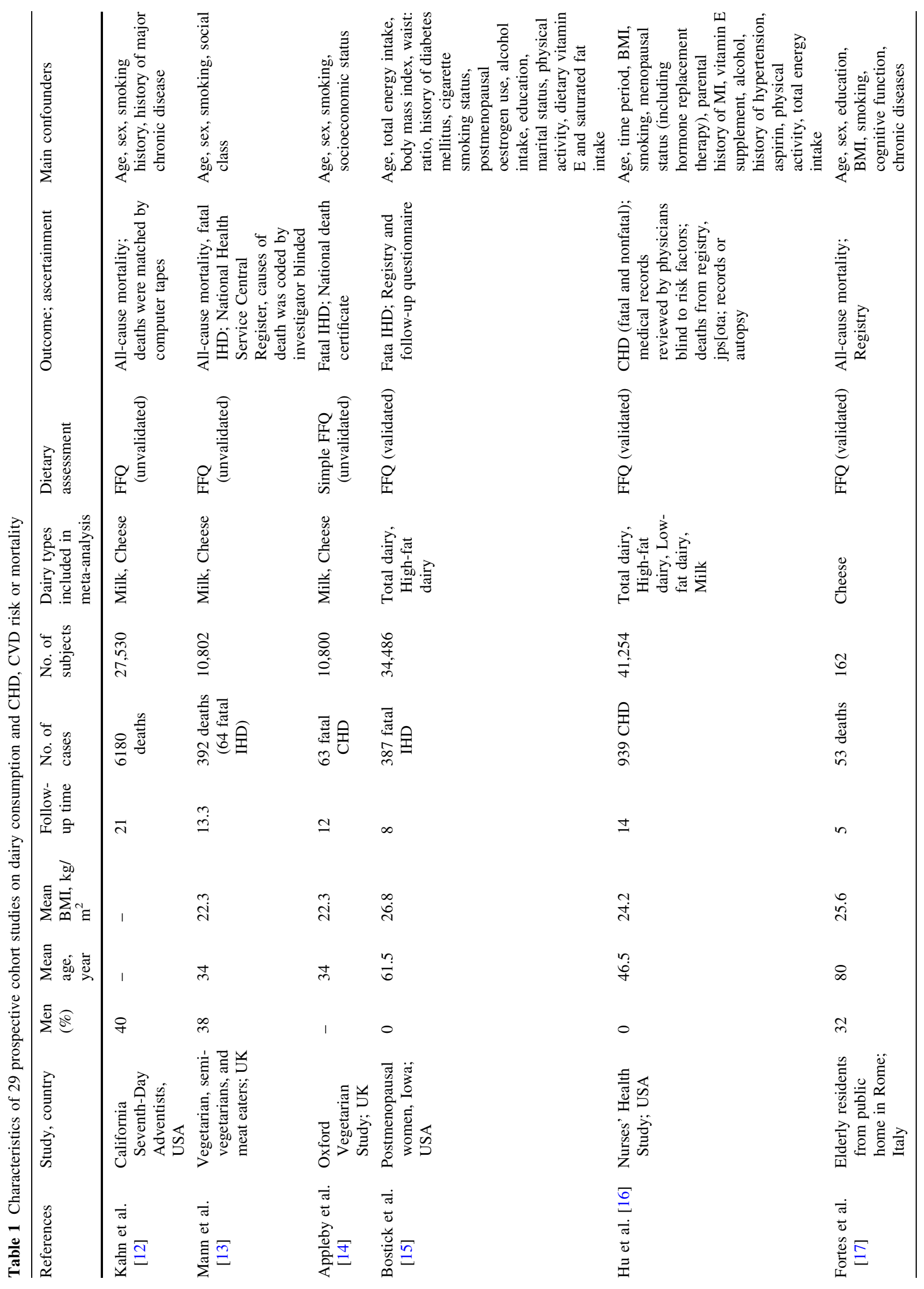




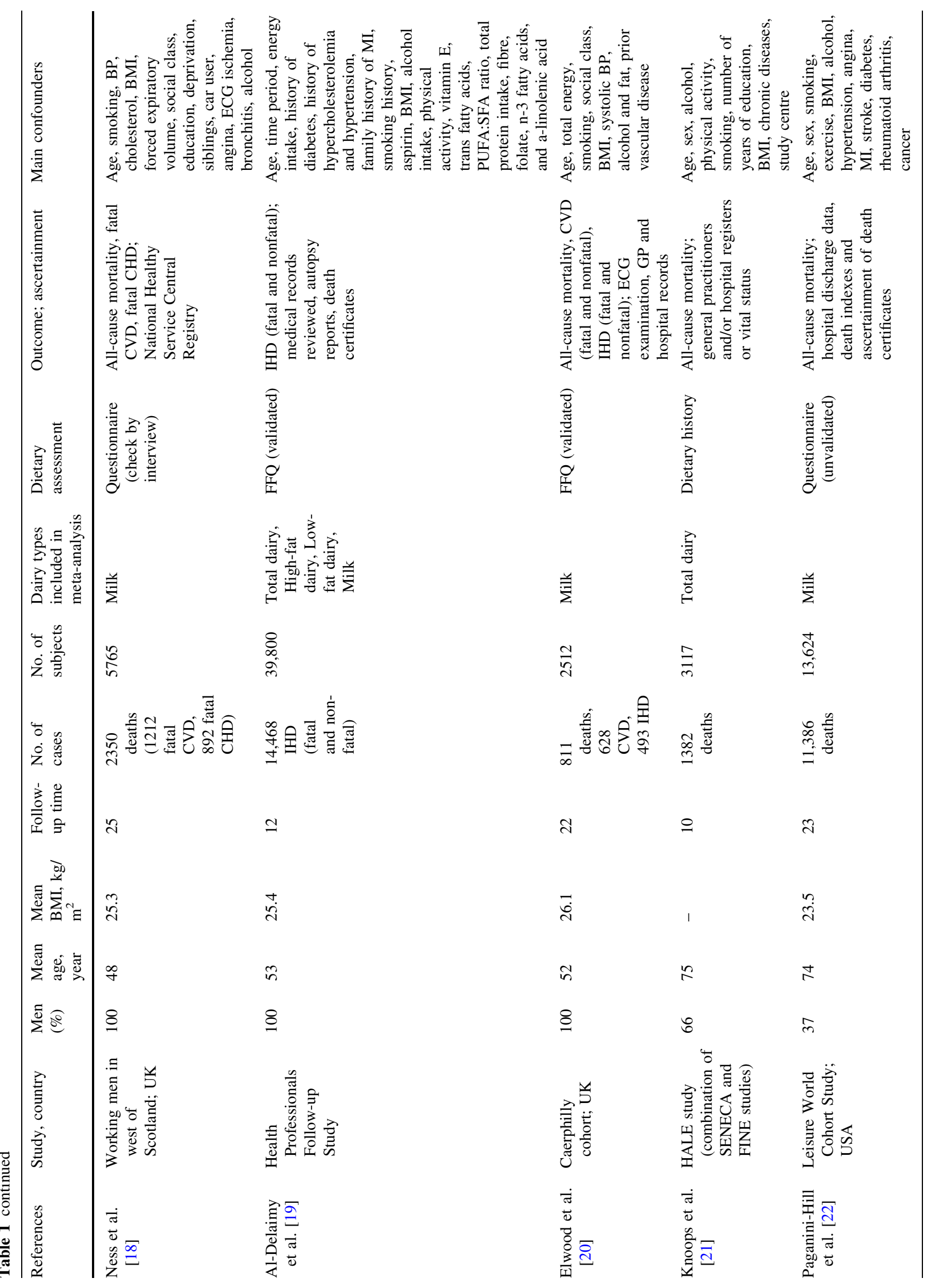




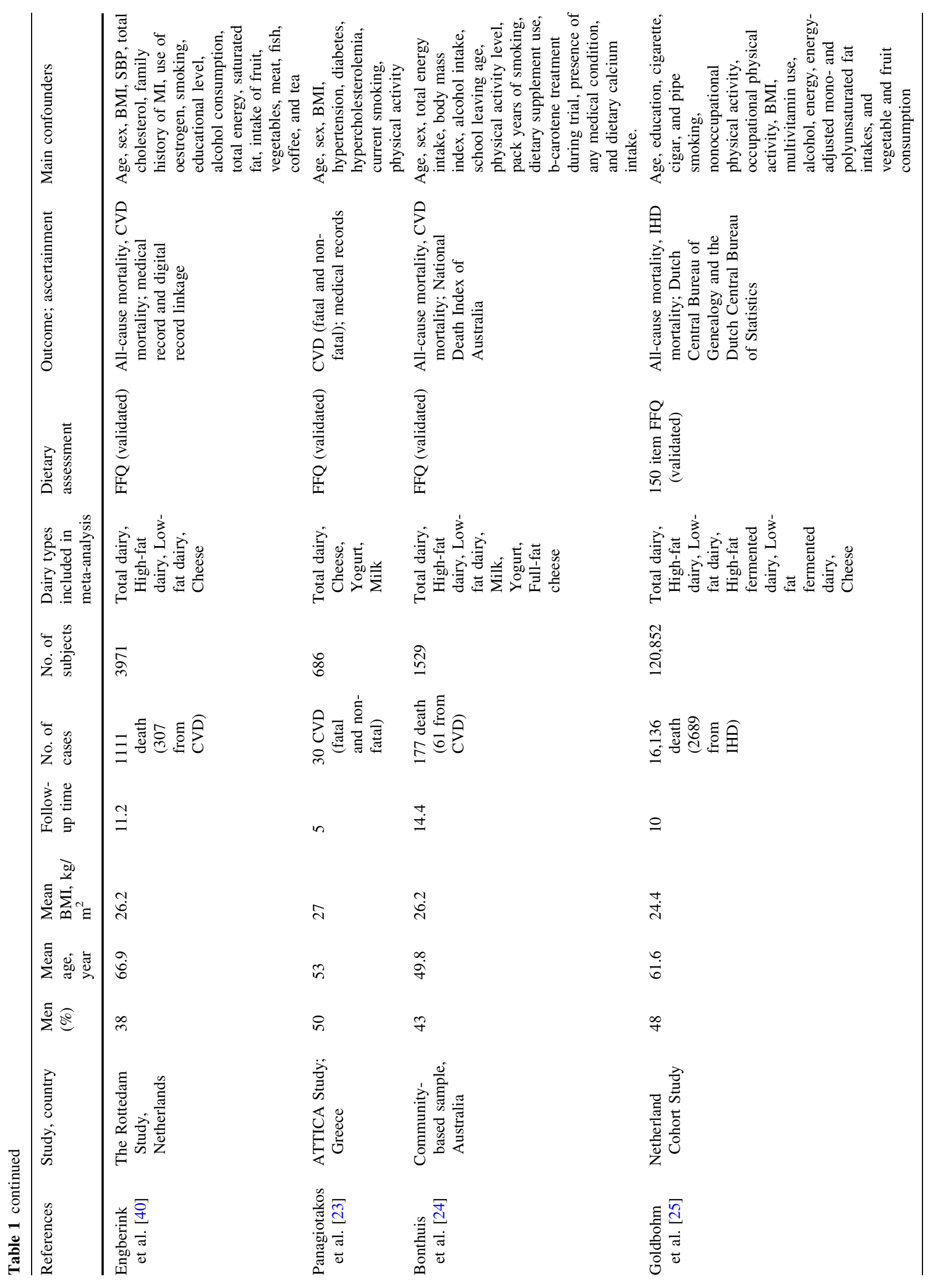




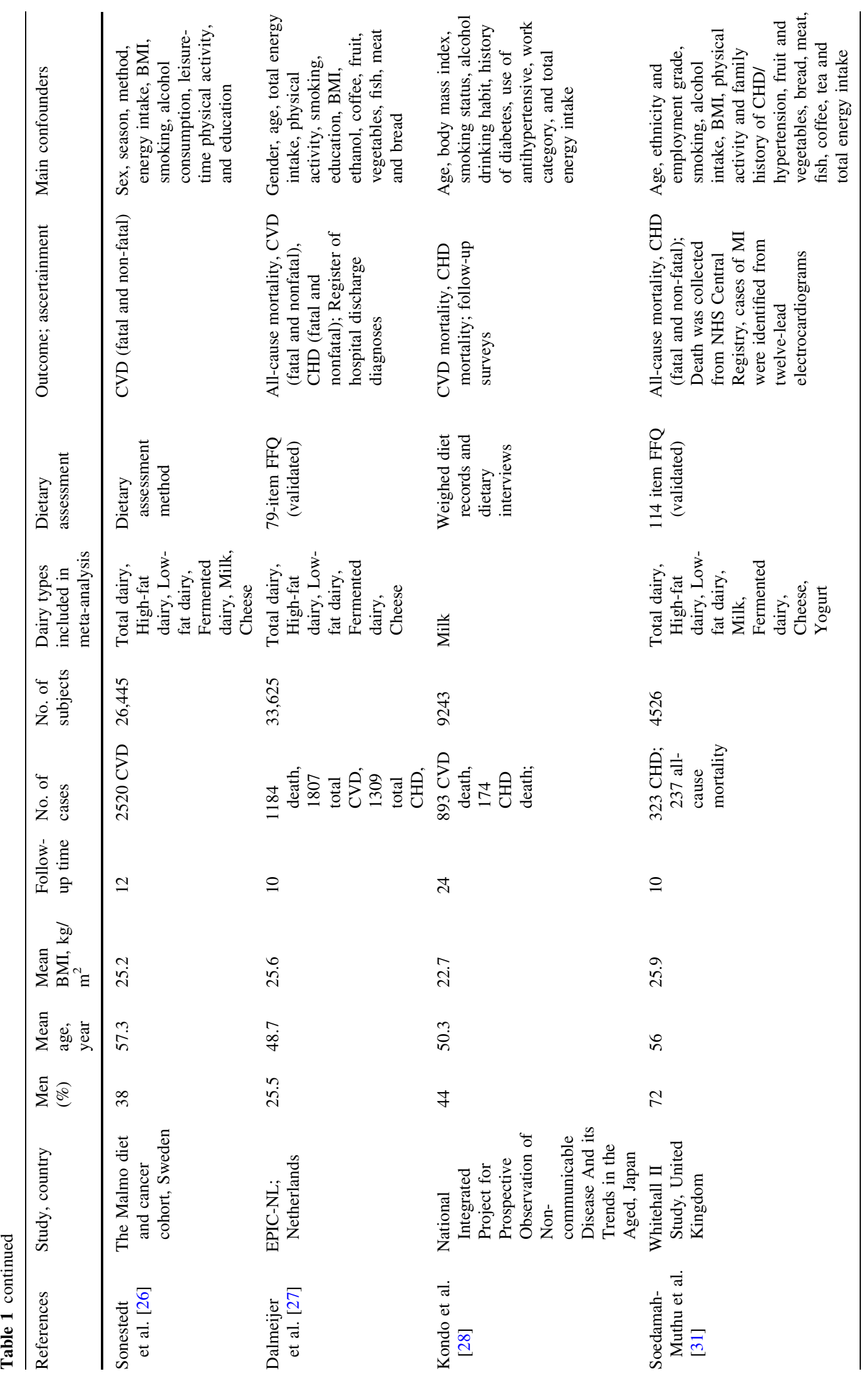




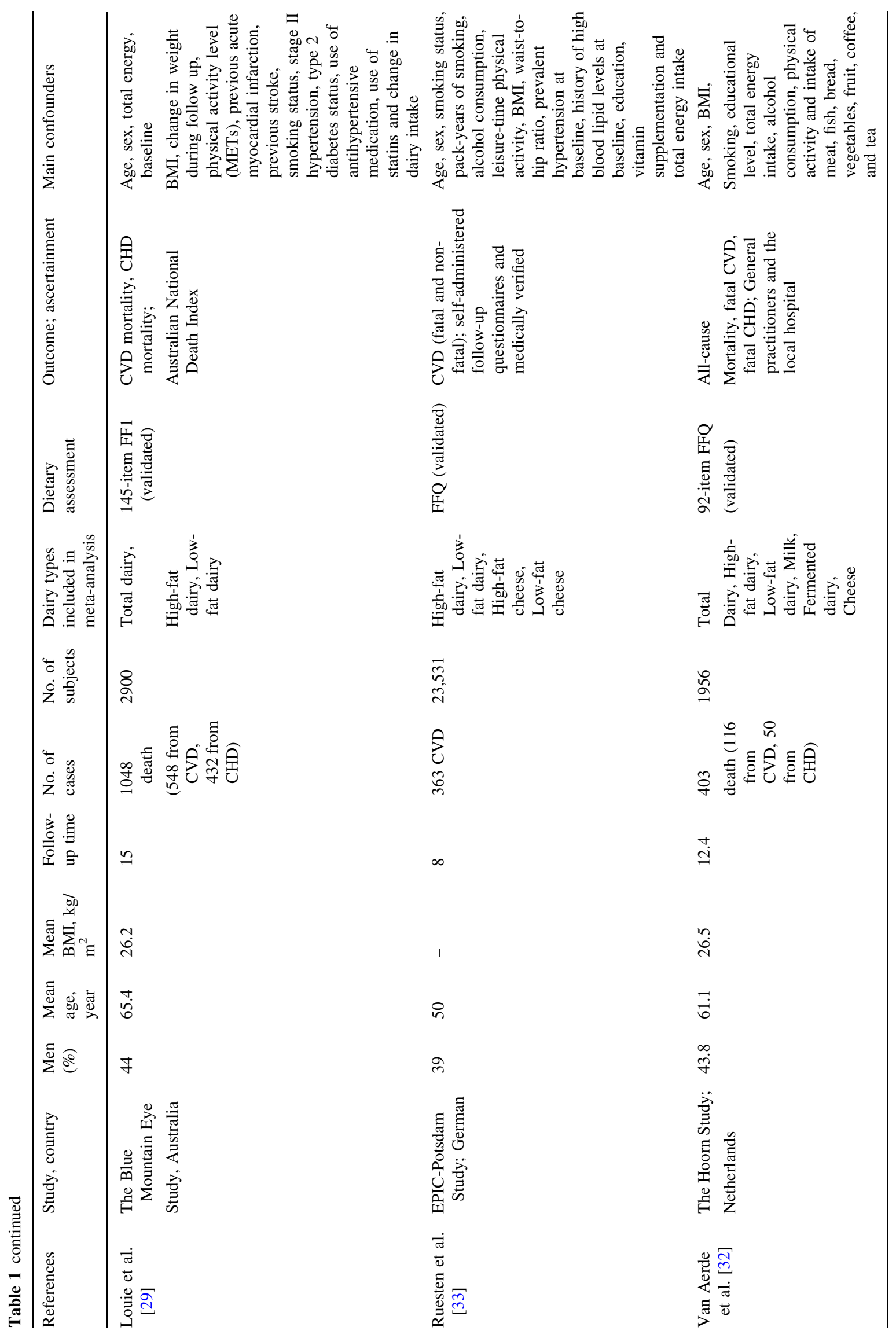




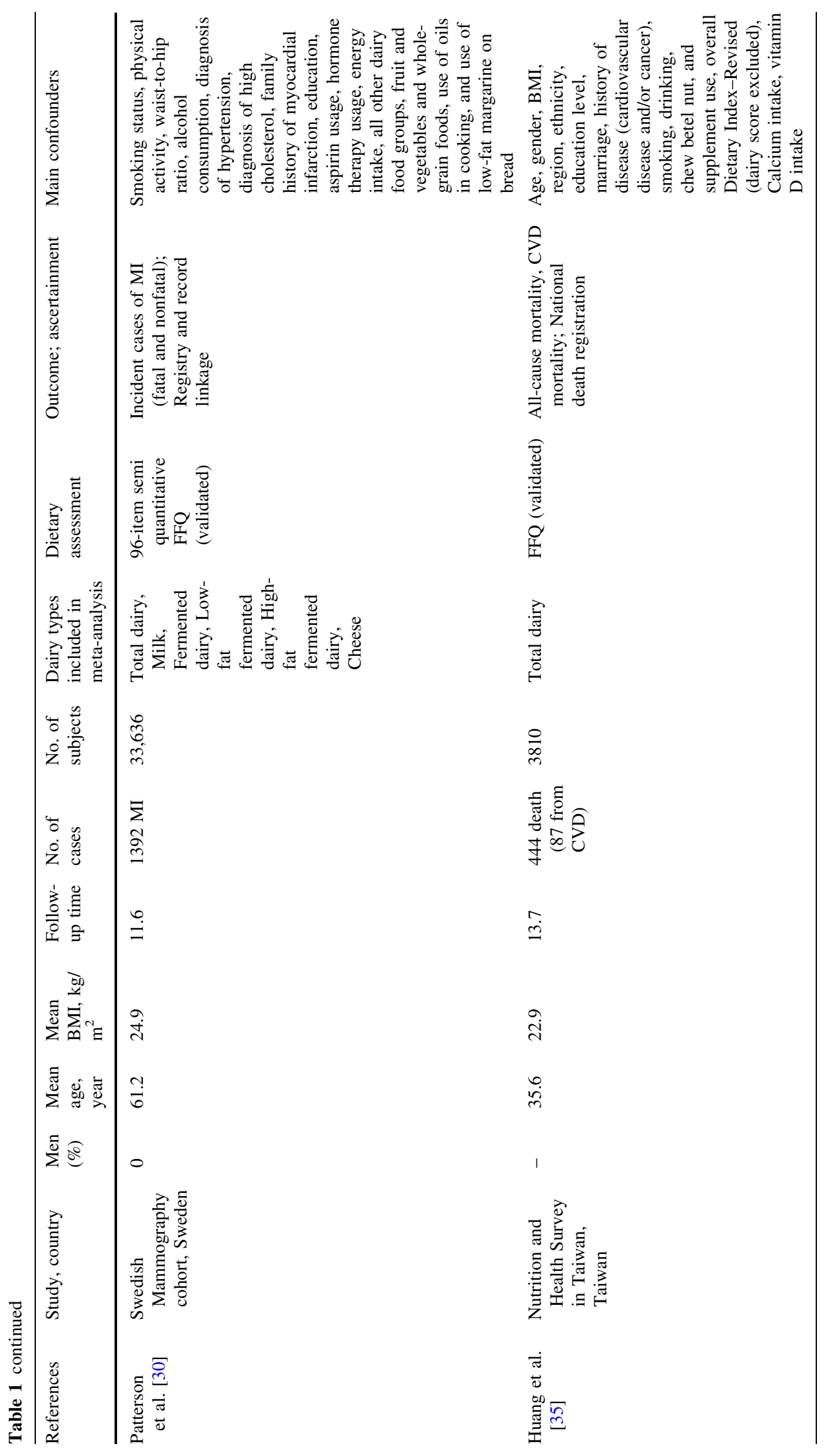




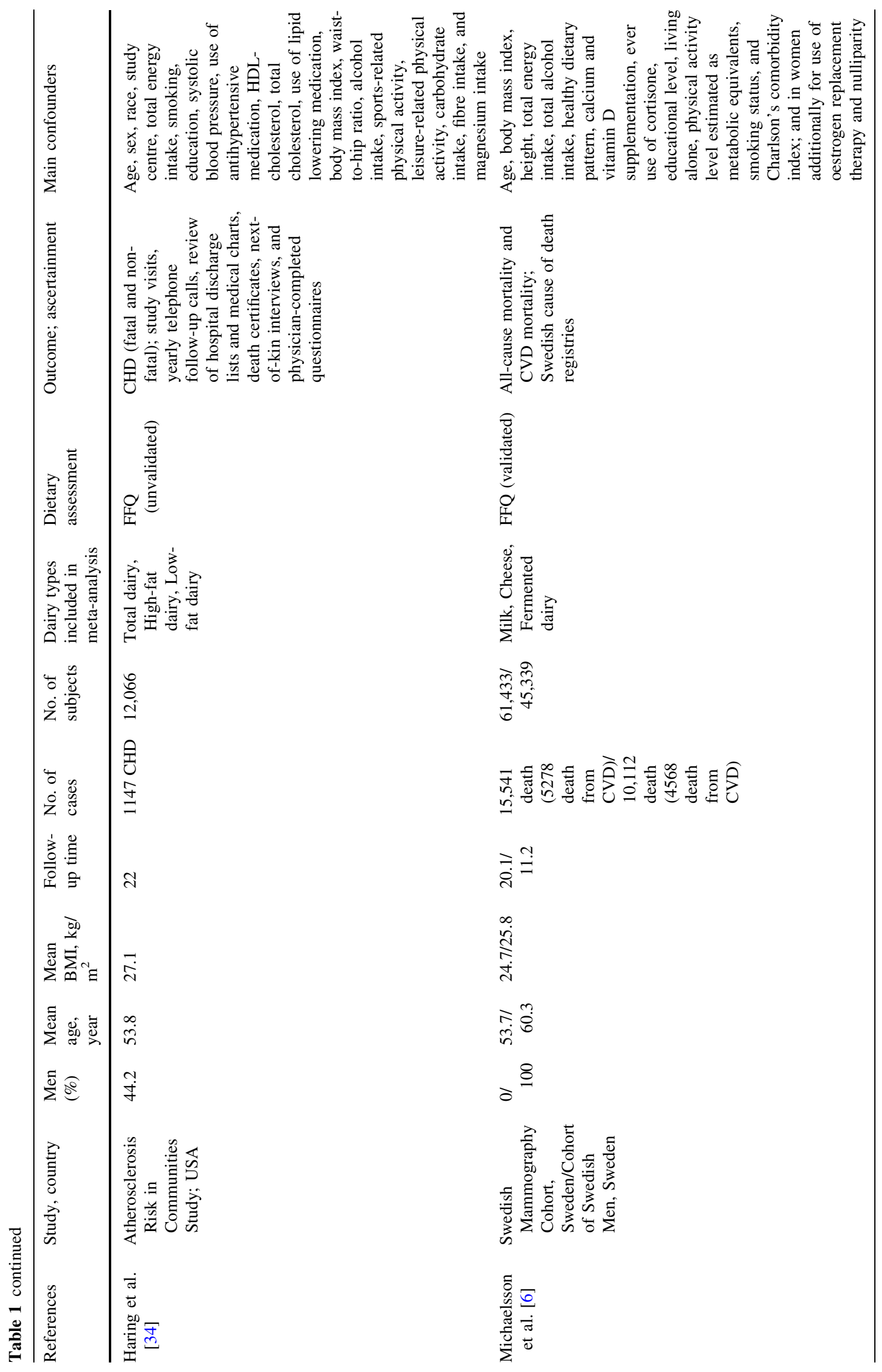




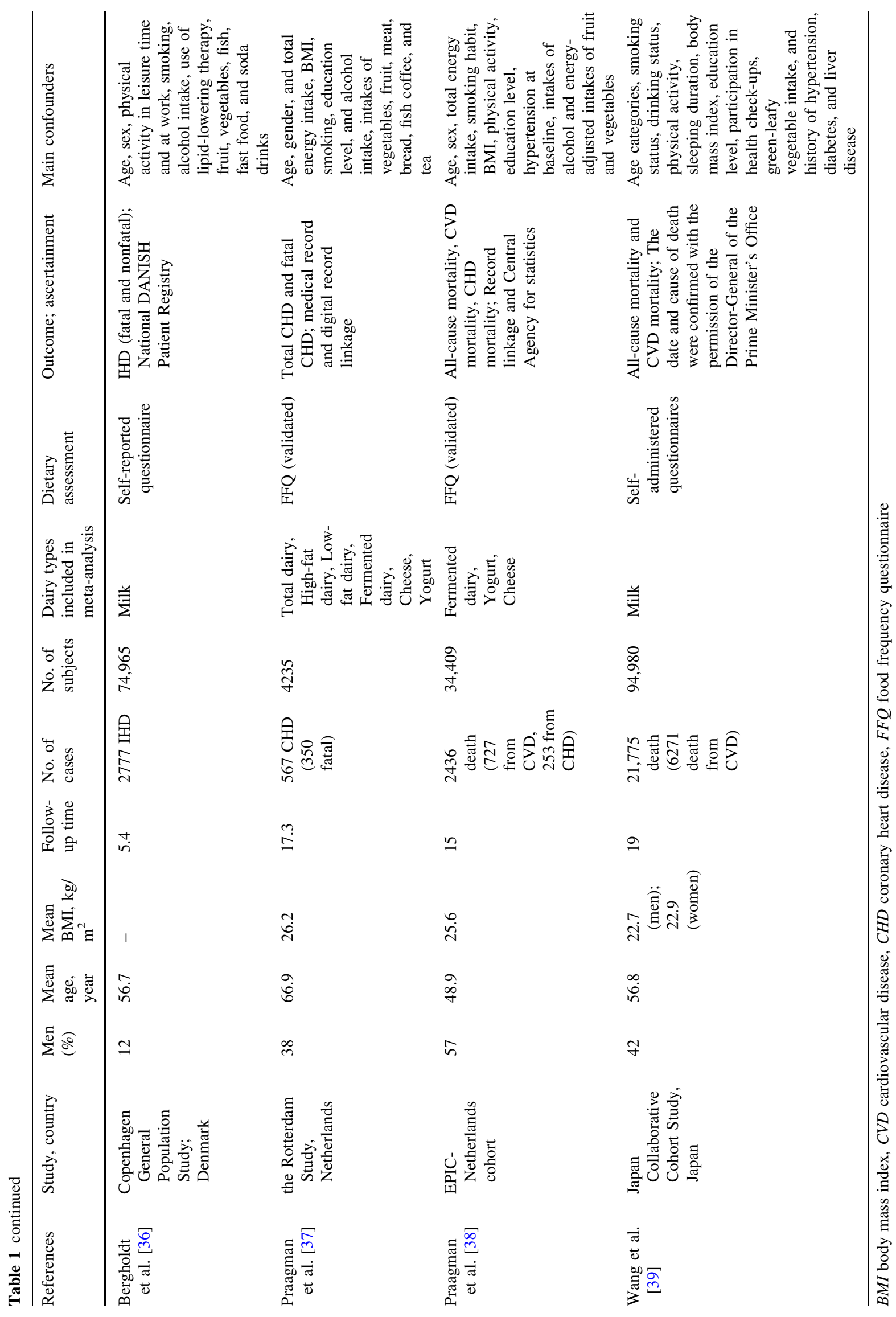


Table 2 Characteristics and results of linear and nonlinear dose response meta-analyses of dairy exposures

\begin{tabular}{|c|c|c|c|c|c|c|c|c|c|}
\hline $\begin{array}{l}\text { Dairy type } \\
\text { (increment } \\
\text { g/day) }\end{array}$ & Outcome & $\begin{array}{l}\text { No studies } \\
\text { (populations) }\end{array}$ & $\begin{array}{l}\text { Mean } \\
\text { age } \\
\text { (years) }\end{array}$ & $\begin{array}{l}\text { Mean } \\
\text { BMI }(\mathrm{kg} / \\
\left.\mathrm{m}^{2}\right)\end{array}$ & $\begin{array}{l}\text { median intake } \\
\text { range (g/day) }\end{array}$ & Total N & $\begin{array}{l}\text { No } \\
\text { events }\end{array}$ & RR $(95 \%$ CI $)$ & $\begin{array}{l}\text { Heterogeneity } \\
\mathrm{I}^{2}(\%), P\end{array}$ \\
\hline \multirow{3}{*}{$\begin{array}{l}\text { Total dairy (per } \\
200 \text { g/day) }\end{array}$} & Mortality & $9(10)$ & 57.2 & 25.2 & $323(0-713)$ & 175,063 & 21,222 & $0.99(0.96,1.03)$ & $62.2,0.005$ \\
\hline & CHD & $11(12)$ & 57.4 & 25.8 & $360(20-828)$ & 330,350 & 8298 & $0.99(0.96,1.02)$ & $38.9,0.081$ \\
\hline & CVD & 8 & 54.4 & 25.6 & $339(0-713)$ & 76,207 & 5525 & $0.97(0.91,1.02)$ & $59.9,0.015$ \\
\hline \multirow{3}{*}{$\begin{array}{l}\text { High-fat dairy } \\
\text { (per } 200 \mathrm{~g} / \text { day) }\end{array}$} & Mortality & 5 & 56.7 & 26.0 & $113(20-339)$ & 47,126 & 3407 & $0.96(0.88,1.05)$ & $0.0,0.603$ \\
\hline & CHD & 9 & 55.9 & 25.9 & $151(19-586)$ & 171,627 & 6661 & $0.99(0.93,1.05)$ & $22.9,0.240$ \\
\hline & CVD & 7 & 57.7 & 25.9 & $130(8-414)$ & 95,242 & 5408 & $0.93(0.84,1.03)$ & $37.4,0.143$ \\
\hline \multirow{3}{*}{$\begin{array}{l}\text { Low-fat dairy } \\
\text { (per } 200 \mathrm{~g} / \text { day) }\end{array}$} & Mortality & $6(7)$ & 58.5 & 25.4 & $217(0-554)$ & 167,978 & 19,543 & $1.01(0.99,1.03)$ & $0.0,0.734$ \\
\hline & CHD & $9(10)$ & 55.5 & 25.7 & $234(0-825)$ & 262,228 & 6244 & $1.00(0.97,1.03)$ & $27.3,0.193$ \\
\hline & CVD & 7 & 57.7 & 25.9 & $211(0-604)$ & 95,242 & 5408 & $0.98(0.95,1.01)$ & $0.0,0.769$ \\
\hline \multirow{3}{*}{$\begin{array}{l}\text { Milk (per } \\
244 \text { g/day) }\end{array}$} & Mortality & $10(12)$ & 55.5 & 24.6 & $268(0-878)$ & 268,570 & 69,355 & $1.00(0.93,1.07)$ & $97.4,<0.001$ \\
\hline & CHD & $11(12)$ & 51.1 & 24.5 & $227(0-877)$ & 230,621 & 8612 & $1.01(0.96,1.06)$ & $45.5,0.043$ \\
\hline & CVD & $9(12)$ & 54.6 & 24.8 & $245(0-878)$ & 249,779 & 21,580 & $1.01(0.93,1.10)$ & $92.4,<0.001$ \\
\hline \multirow{3}{*}{$\begin{array}{l}\text { Fermented dairy } \\
\text { (per } 20 \mathrm{~g} / \text { day) }\end{array}$} & Mortality & $11(19)$ & 57.0 & 25.2 & $70(0-500)$ & 378,058 & 98,536 & $0.98(0.97,0.99)$ & $94.4,<0.001$ \\
\hline & CHD & $9(14)$ & 53.7 & 25.0 & $96(0-417)$ & 256,091 & 5667 & $0.99(0.98,1.01)$ & $44.6,0.037$ \\
\hline & CVD & $9(17)$ & 54.8 & 25.8 & $105(0-627)$ & 271,071 & 33,980 & $0.98(0.97,0.99)$ & $87.5,<0.001$ \\
\hline \multirow{3}{*}{$\begin{array}{l}\text { Cheese (per } \\
10 \text { g/day) }\end{array}$} & Mortality & $11(13)$ & 57.2 & 25.2 & $25(1-70)$ & 342,120 & 54,125 & $0.99(0.96,1.01)$ & $93.3,<0.001$ \\
\hline & CHD & $9(10)$ & 53.8 & 25.0 & $34(3-192)$ & 256,091 & 4022 & $0.99(0.97,1.02)$ & $40.3,0.089$ \\
\hline & CVD & $9(11)$ & 55.3 & 25.8 & $34(0-103)$ & 234,447 & 15,519 & $0.98(0.95,1.00)$ & $82.6,<0.001$ \\
\hline \multirow{3}{*}{$\begin{array}{c}\text { Yogurt (per } \\
50 \text { g/day) }\end{array}$} & Mortality & 3 & 51.3 & 25.9 & $46(0-145)$ & 40,460 & 2850 & $0.97(0.85,1.11)$ & $65.8,0.054$ \\
\hline & CHD & 3 & 56.4 & 25.9 & $60(0-145)$ & 98,936 & 1143 & $1.03(0.97,1.09)$ & $0.0,0.685$ \\
\hline & CVD & 3 & 50.6 & 26.3 & $147(0-627)$ & 36,624 & 817 & $1.03(0.97,1.09)$ & $0.0,0.499$ \\
\hline
\end{tabular}

$P=0.005)$ and $\operatorname{CVD}\left(\mathrm{I}^{2}=59.9 \%, P=0.015\right)$ but not CHD $\left(\mathrm{I}^{2}=38.9 \%, P=0.081\right)$. In sensitivity analyses, heterogeneity among studies of the mortality could be reduced to $50 \%(P=0.042)$ with a RR of $1.00(95 \% \mathrm{CI}$ $0.97-1.04)$ by excluding the study of Soedamah-Muthu et al. [31]; the heterogeneity among studies of CVD was reduced $\left(\mathrm{I}^{2}=11.2, P=0.338\right)$ after removing the study of $\mathrm{Hu}$ et al. [16] with a resulting RR of 0.98 (95\% CI 0.96-1.00). Sub-group analyses of CHD (Supplemental Table 4) indicated inverse associations for study populations with a mean age $>50$ years (RR $0.97,95 \%$ CI $0.94-1.00,8$ populations) and also for studies which did not adjust for 7 major confounders defined in methods as age, sex, smoking, alcohol, BMI, physical activity, food energy intake (RR 0.94, 95\% CI $0.88-1.00,3$ populations).

High-fat dairy intake (per $200 \mathrm{~g} /$ day) showed no association with mortality (Supplemental Figure 4; RR 0.96, 95\% CI $0.88-1.05,5$ populations), CHD (Supplemental Figure 5; RR 0.99, 95\% CI 0.93-1.05, 9 populations) or CVD (Supplemental Figure 6; RR 0.93, 95\% CI 0.84-1.03, 7 populations), and there was no significant heterogeneity. In sensitivity analyses of the association between high-fat dairy and CHD, I-squared was reduced from $22.9 \%$ $(P=0.240)$ to $0 \%(P=0.464)$ with results of RR 1.01 ,
95\% CI 0.96-1.06) after removing the study of Dalmeijer et al. [27]. Also, sensitivity analyses of the association between high-fat dairy and CVD showed I-squared reduced to $0 \%(P=0.143)$ with results of RR 0.98 (95\% CI 0.93-1.03) after excluding study Bonthuis et al. [24]. Subgroup analysis of CVD by age showed a stronger inverse association between high-fat dairy intake and CVD risk in the subjects $\leq 50$ years (RR 0.76, 95\% CI 0.59-0.97, 3 populations), although the sample size was small. There was no heterogeneity $\left(\mathrm{I}^{2}=31.5 \%, P=0.232\right)$.

Low-fat dairy intake (per $200 \mathrm{~g} /$ day) was not significantly associated with mortality (Supplemental Figure 7; RR 1.01, 95\% CI 0.99-1.03, 7 populations), CHD (Supplemental Figure 8; RR 1.00, 95\% CI 0.97-1.03) or CVD (Supplemental Figure 9; RR 0.98, 95\% CI 0.95-1.01). No heterogeneity was found in the meta-analysis on low-fat dairy. In the sub-group analysis for CVD (Supplemental Table 5) on subjects whose BMI $>25 \mathrm{~kg} / \mathrm{m}^{2}$, low-fat dairy intake was inversely associated with the risk of CVD (RR $0.97,95 \%$ CI $0.94-1.00,6$ populations).

\section{Milk}

Milk intake (per $244 \mathrm{~g} /$ day, 12 populations) was not associated with all-cause mortality (Supplemental 


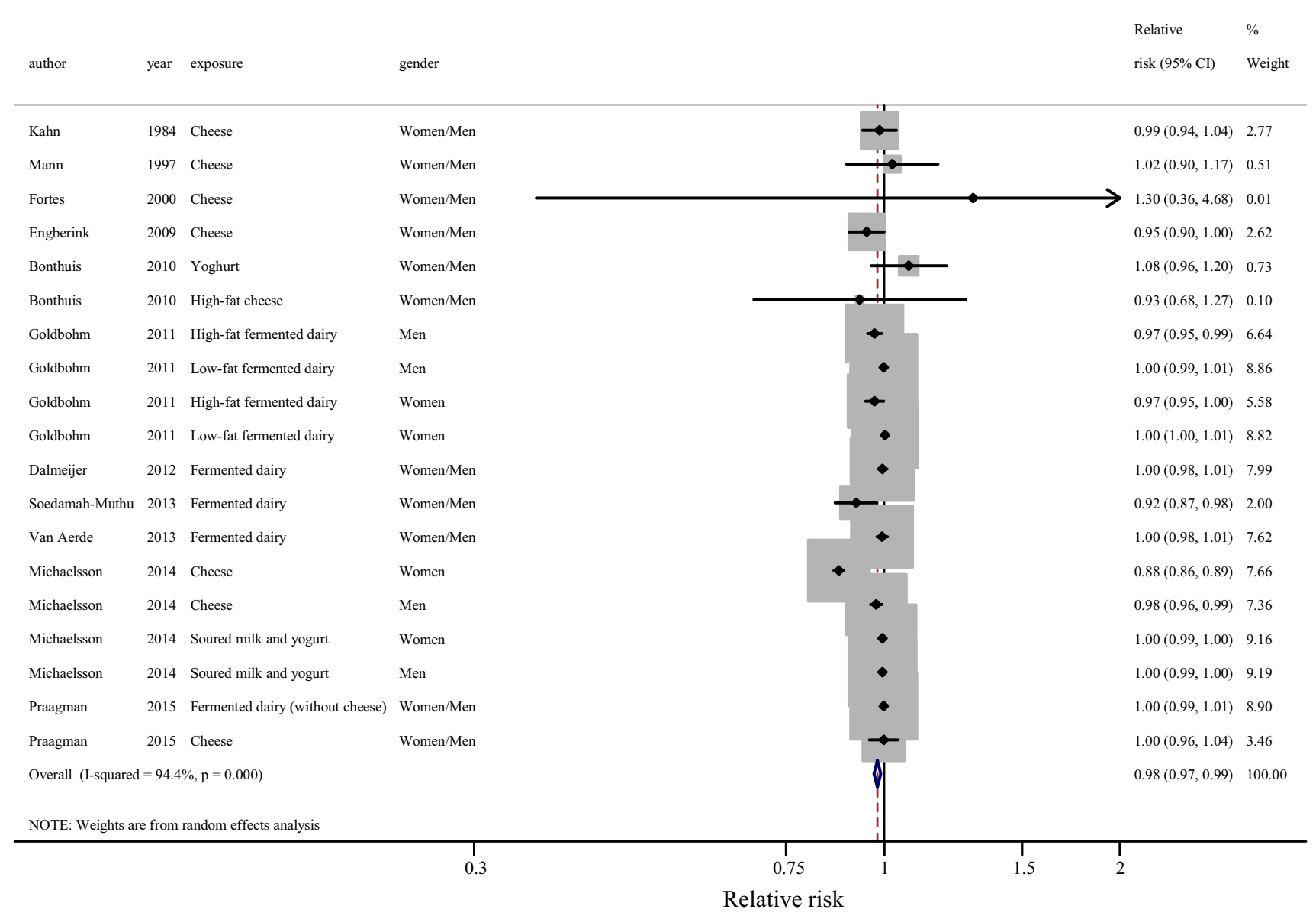

Fig. 2 Relative risk of all-cause mortality for an increment of $20 \mathrm{~g} /$ day of fermented dairy intake. Squares represent study-specific RR. Square areas are proportional to the overall specific-study weight to the overall meta-analysis. Horizontal lines represent $95 \%$ CIs.

Figure 10; RR 1.00, 95\% CI 0.93-1.07), CHD (Supplemental Figure 11; RR 1.01, 95\% CI 0.96-1.06) or CVD (Supplemental Figure 12; RR 1.01, 95\% CI 0.93-1.10). Significant heterogeneity was present for all-cause mortality $\left(\mathrm{I}^{2}=97.4, P<0.001\right)$, $\mathrm{CHD}\left(\mathrm{I}^{2}=45.5, P=0.043\right)$ and CVD $\left(\mathrm{I}^{2}=92.4, P<0.001\right)$. In sensitivity analyses for the association between milk and all-cause mortality by excluding data of Michaelsson et al. [6] for women, $\mathrm{I}^{2}$ reduced to $70.1 \%(P<0.001)$ with RR $0.99(95 \% \mathrm{CI}$ 0.96-1.01). By removing Kondo et al. [28] from the metaanalysis of CHD, heterogeneity reduced $\left(\mathrm{I}^{2}=35.10\right.$, $P=0.118$ ) with a RR of 1.01 (95\% CI 0.97-1.05). Results of high-fat milk or low-fat milk were not reported, as only one study [30] was available for the effect of high-fat milk or low-fat milk in relation to CHD. Sub-group analyses showed an inverse association between milk consumption and mortality (Supplemental Table 3 ) in the subgroup of studies with a mean age $\leq 50$ years ( 3 populations without heterogeneity $\left(\mathrm{I}^{2}=0 \%, P=0.479\right)$. Also, inverse associations were found between milk intake and CVD
Diamonds represent the pooled relative risk and $95 \%$ CIs. By excluding the Swedish study [6] of women's results for cheese, $\mathrm{RR}=1.00(95 \%$ CI $0.99-1.00), \mathrm{I}^{2}=45.2 \%(P=0.02)$

(Supplemental Table 5) for the studies which did not adjust for 7 confounders (age, sex, smoking, alcohol, BMI, physical activity, food energy intake) (RR $0.94,95 \%$ CI $0.89-0.99 ; \mathrm{I}^{2}=28.6, P=0.210$ ) or for the NOS score $<7$ (RR 0.95, 95\% CI 0.90-1.00; $\mathrm{I}^{2}=22.1, P=0.278$ ).

\section{Total fermented dairy, cheese and yogurt}

Total fermented dairy intake (weighted median intake $77 \mathrm{~g} /$ day, 19 populations, 11 studies) was non-linearly and marginally associated with lower mortality risk, with a RR of 0.98 (95\% CI $0.97-0.99$ ) per $20 \mathrm{~g} /$ day but with high heterogeneity $\left(\mathrm{I}^{2}=94.4 \%, P<0.001\right.$; Fig. 2$)$. In sensitivity analysis, by excluding the Swedish study [6] of women's results for cheese, $\mathrm{I}^{2}$ was reduced to $45.2 \%$ $(P=0.02)$, with RR of 1.00 (95\% CI 0.99-1.00). Similarly, total fermented dairy intake (17 populations, 9 studies) was non-linearly and modestly associated with a $2 \%$ lower CVD risk per $20 \mathrm{~g} /$ day (RR $0.98,95 \%$ CI 0.97-0.99) (Fig. 3). Significant heterogeneity was present 


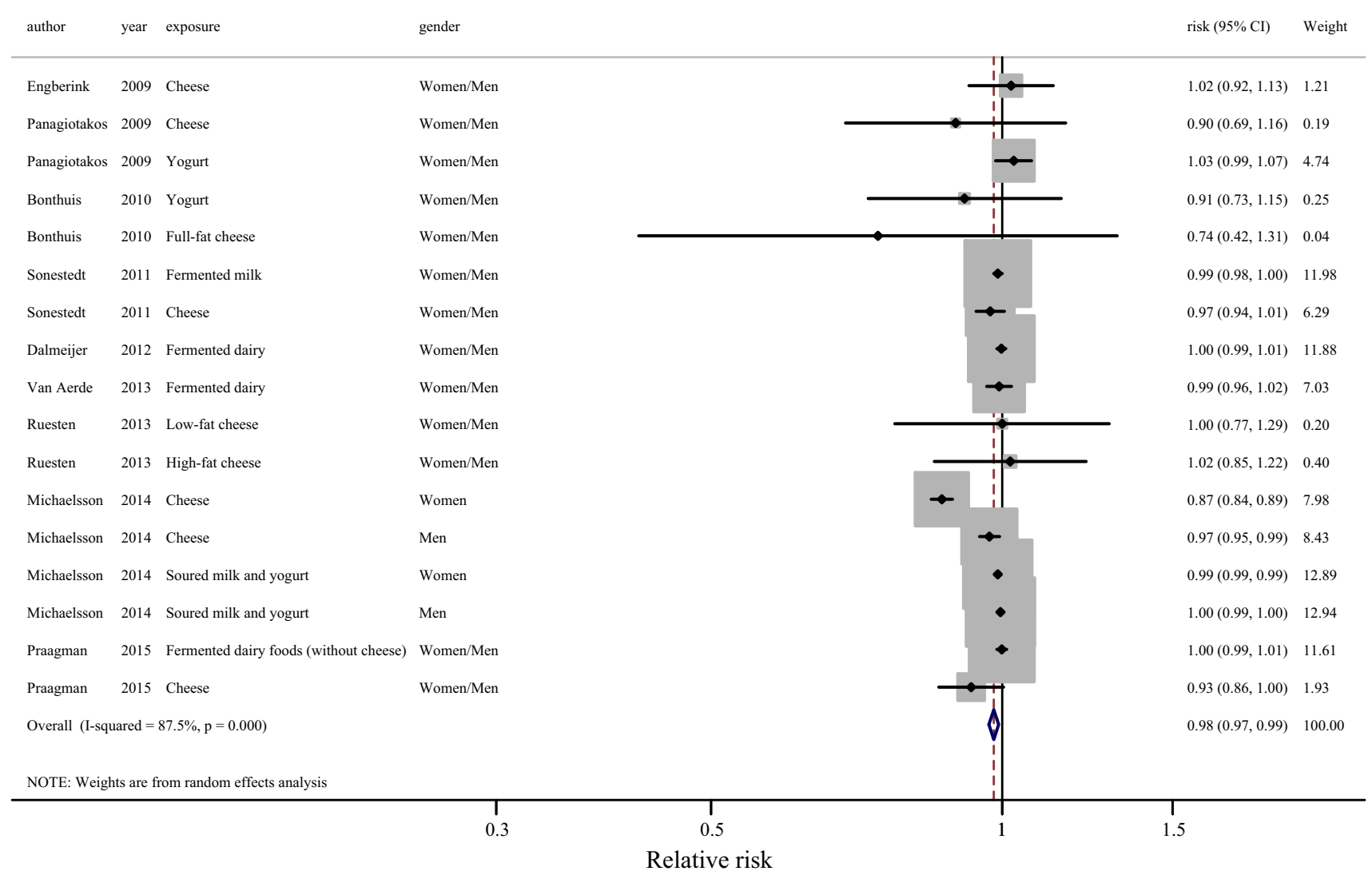

Fig. 3 Relative risk of CVD for an increment of $20 \mathrm{~g} /$ day of fermented dairy intake. Squares represent study-specific RR. Square areas are proportional to the overall specific-study weight to the overall meta-analysis. Horizontal lines represent $95 \%$ Cis. Diamonds

$\left(\mathrm{I}^{2}=87.5 \%, P<0.001\right)$. Again, in a sensitivity test, excluding the Swedish study [6] of women's results for cheese, showed a marked decrease in heterogeneity to $23.8 \%(P=0.19)$, with a $1 \%$ lower CVD risk (RR 0.99, 95\% CI 0.99-1.00). Total fermented dairy intake (14 populations, 9 studies) showed no association with CHD risk, with a RR of 0.99 (95\% CI $0.98-1.01)$ per $20 \mathrm{~g} /$ day increment with no indications of a nonlinear association (Supplementary Figure 13). The heterogeneity in the CHD and total fermented dairy data was significant $\left(\mathrm{I}^{2}=44.6 \%\right.$, $P=0.037)$. In sensitivity analyses, after excluding the study of Patterson et al. [30], the heterogeneity for cheese was reduced $\left(\mathrm{I}^{2}=32.5 \% ; P=0.122\right)$, but with results remaining similar with a RR of 1.00 (95\% CI 0.99-1.01).

Cheese (per $10 \mathrm{~g} / \mathrm{day}$ ) was marginally non-linearly inversely related to CVD (Fig. 4; RR 0.98, 95\% CI $0.95-1.00 ; 11$ populations), but not to risk of mortality (Supplementary Figure 14; RR 0.99, 95\% CI 0.96-1.01; 13 populations) or CHD (Supplementary Figure 15; RR 0.99, 95\% CI 0.97-1.02). Significant heterogeneity was seen for mortality $\left(\mathrm{I}^{2}=93.3 \%, P<0.001\right)$ or $\mathrm{CVD}\left(\mathrm{I}^{2}=82.6 \%\right.$, represent the pooled relative risk and 95\% CIs. By excluding the Swedish study [6] of women's results for cheese, RR $=0.99$ (95\% CI $0.99-1.00), \mathrm{I}^{2}=23.8 \%(P=0.19)$

$P<0.001)$. In sensitivity analyses, heterogeneity was reduced after removal of the large Swedish study [6] $\left(\mathrm{I}^{2}=11 \%, P=0.337\right.$ for mortality; $\mathrm{I}^{2}=0 \%, P=0.835$ for CVD), with no association for mortality and CVD $(\mathrm{RR}=1$ for both).

Yogurt ( 3 populations) was not associated with all-cause mortality $\left(\mathrm{I}^{2}=65.8 \%, P=0.054, \mathrm{RR} 0.97,95 \% \mathrm{CI}\right.$ $0.85-1.11)$, CHD $\left(\mathrm{I}^{2}=0 \%, P=0.685\right.$, RR $1.03,95 \%$ CI $0.97-1.09)$ or $\mathrm{CVD}\left(\mathrm{I}^{2}=0 \%, P=0.499\right.$, RR $1.03,95 \%$ CI 0.97-1.09) (Supplementary Figure 16-18).

\section{Discussion}

This meta-analysis combining data from 29 prospective cohort studies showed there were no associations between total dairy, high- and low-fat dairy, milk and the health outcomes including all-cause mortality, CHD or CVD. The modest inverse associations of total fermented dairy were found with all-cause mortality and CVD, but not CHD. By examining different types of fermented food in relation to 


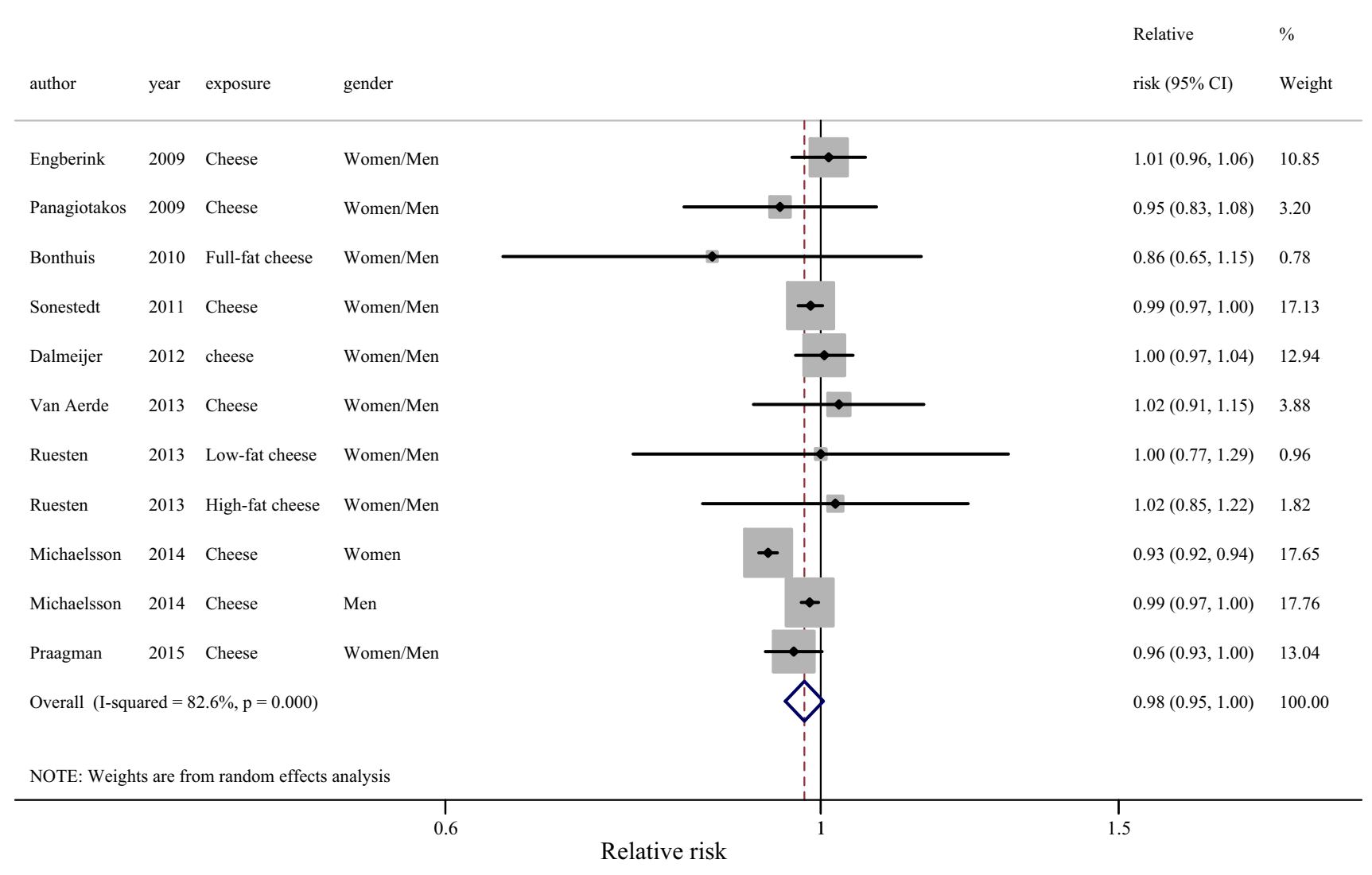

Fig. 4 Relative risks of CVD for an increment of $10 \mathrm{~g} /$ day of cheese. Squares represent study-specific RR. Square areas are proportional to the overall specific-study weight to the overall meta-analysis. Horizontal lines represent $95 \%$ CIs. Diamonds represent the pooled

CVD, we found marginally inverse association with cheese but not yogurt. However, further sensitivity tests showed the inverse associations of fermented dairy and cheese with all-cause mortality or CVD disappeared after removing the study of Michaelsson et al. [6].

No associations were found between total dairy and milk consumption with all-cause mortality, CHD or CVD in the current study, which is in agreement with several metaanalyses [47, 48]. Larsson et al. [47] reported neutral associations of dairy and milk consumption with mortality or CVD mortality. Mullie et al. [48] reported neutral associations of milk consumption with all-cause mortality or CHD. In addition, the current study is in agreement with a recently published review [49] which indicated neutral associations between the consumption of total dairy and risk of CHD or CVD. Results of sub-group analyses showed the inverse associations were observed between total dairy intake and CHD, or the association between milk consumption and CVD when studies did not adjust for major confounders. Thus, confounders included in statistical analyses in prospective studies have substantial effects on the final findings and conclusions. Furthermore, inverse associations were also found in sub-groups of studies relative risk and $95 \%$ Cis. By excluding the Swedish study [6] of women's results for cheese, $\mathrm{RR}=0.99(0.98-0.99), \quad \mathrm{I}^{2}=0 \%$ $(P=0.84)$

defined by mean age $(\leq 50,>50$ years $)$ or BMI $(>25 \mathrm{~kg} /$ $\mathrm{m}^{2}$ ) of the associations between total, high-fat, low-fat dairy and milk with risk of all-cause mortality, CHD or CVD, which indicated the findings and conclusions were also affected by characteristics of the study populations within different studies.

Three US prospective cohort studies described by Chen et al. [50] showed a substantially lower risk of CVD when animal fats, including dairy fat, were replaced by unsaturated fats. Recently, UK National Health Service (NHS) has recommended low-fat milk and dairy products as healthy choices [51]. However, in the current study, highfat and low-fat dairy consumption were investigated separately and no substitution models replacing high by lowfat dairy products were carried out. We found no significant associations between high-and low-fat dairy and all-cause mortality, CHD or CVD. This supports two previous metaanalyses [5, 52] which also reported no association of high or low-fat dairy and CHD. Furthermore, beneficial effects of high-fat dairy foods on human health were reported by a cross-sectional study [53], which showed an inverse association of full-fat dairy food and the metabolic syndrome. In addition, another US study [54], which reviewed cross- 
sectional and prospective cohort studies, showed that 11 of the 16 studies identified that population with higher full-fat dairy intake had less adiposity. It is also noteworthy that butter as a high fat dairy food containing $80 \%$ fat [55], a recent meta-analysis on the effects of butter [10] showed that whilst consumption was weakly associated with allcause mortality (per $14 \mathrm{~g} /$ day: RR 1.01, 95\% CI 1.00-1.03), there was no significant association with CHD, CVD or stroke and there was an inverse association with incidence of diabetes (RR 0.96, 95\% CI 0.93-0.99). Therefore, the effect of dairy fat on CVD is complex and may be influenced by the nature of the fat containing food vehicle, which needs confirmation in further studies.

Despite their fat content and composition, milk and dairy products are naturally rich in various minerals (e.g. calcium, potassium), protein and vitamins (e.g. vitamin A and vitamin $B_{12}$ ) [56]. Nutrients including calcium, potassium and magnesium have been suggested to be associated with lower risk of stroke [57, 58]. Short-term human intervention studies $[59,60]$ also indicated that subjects who have high-fat diets enriched with dairy minerals or calcium have significantly lower total cholesterol and LDL-cholesterol levels than those on a control diet. This may explain in part why total dairy consumption has a neutral role in terms of the effect on health outcomes.

The current study also showed total fermented dairy and cheese intake to be marginally inversely associated with mortality and CVD risk, respectively, and large heterogeneity was present. However, by removing the study of Michaelsson et al. [6], heterogeneity of the associations of total fermented dairy and mortality or CVD, cheese and mortality or CVD were markedly reduced. Also, the marginally inversely associations were disappeared. To our knowledge, the present study is the first dairy meta-analysis to include the large Swedish cohort results [6]. The markedly reduced heterogeneity after removing the results of the Swedish female cohort [6] indicated the heterogeneous nature of the Swedish study, which may be related to the diet and lifestyle characteristics of the study participants, as they had a relatively low education level ( 80 and $70 \%$ for women and men were educated for $\leq 9$ years, respectively), also the highest milk drinkers had highest percentage of smokers and those living alone.

Cheese consumption based on 11 populations was found to be modestly and inversely associated with CVD risk, with a $2 \%$ lower risk of CVD per $10 \mathrm{~g}$ /day of cheese, however, the significant association disappeared after removing the study of Michaelsson et al. [6]. Compared with other meta-analyses on cheese, Alexander et al. [4] has reported $11 \%$ lower risk of CVD per $35 \mathrm{~g} /$ day $(95 \% \mathrm{CI}$ 0.78-1.01), while Chen et al. [61] presented $10 \%$ lower risk of CHD per $50 \mathrm{~g} /$ day (95\% CI 0.84-0.95). However, the analysis of the associations between cheese and CVD in studies of Alexander et al. [4] and Chen et al. [61] were based on 3 and 8 populations, respectively, which was less than our current study of 11 populations.

Furthermore, total fermented dairy and cheese were modestly inversely associated with risk of CVD but not CHD in the current meta-analysis, so perhaps both dairy types play a role in reducing the risk of stroke. This is supported by the evidence of another recent meta-analysis [9], which found a 9\% lower risk of stroke (RR 0.91, 95\% CI 0.82-1.01) associated with higher total fermented dairy intake and a 3\% lower risk of stroke (RR 0.97, 95\% CI 0.94-1.01) with higher cheese consumption, although none of these associations were statistically significant. As there was limited information of the different sub-types of the CVD events, the understanding of the association of fermented dairy products with varied CVD types remains unclear. In addition, unlike the result for cheese, the association of yogurt with disease outcomes was neutral. However, a previous review of randomised trials suggested that yogurt is associated with lower risk of CVD [62]. Our null results for yogurt intake and CVD may be due to the limited number of participants from only 3 populations. In addition, a very recent meta-analysis showed a $14 \%$ lower risk of type 2 diabetes for $80 \mathrm{~g} /$ day yogurt intake (RR 0.86 , 95\% CI $0.83-0.90$ ) based on 11 prospective cohort studies [63].

The mechanism of the beneficial association of fermented dairy products and reduced CVD risk and mortality is uncertain. Evidence from randomised controlled trials suggests that the reason, at least in part, may be an effect of the food matrix reducing lipid absorption and short chain fatty acids produced by the bacteria in the large intestine [64]. Moreover, omics-techniques have suggested that some of the beneficial effects of cheese can be accounted for by microbial fermentation producing short chain fatty acids such as butyrate [65].

Strengths of our study include the use of dose-response meta-analysis, the inclusion of more studies than in previous meta-analyses and the consideration of examination the individual dairy products separately such as dairy products in terms of fat content (high-fat, low-fat) or processing method (fermented or non-fermented). However, investigation of total dairy or total fermented dairy consumption with disease outcomes by combining dairy foods, high and low-fat dairy foods, solids and liquids, simply adding these up is a limitation which should be addressed in future studies by collecting and analyzing more detailed data. In addition, limitations of the study include sub-group analyses that lack statistical power, such as for Asian studies and effects of gender. We have 9 studies with scores of 7 or less by using the Newcastle-Ottawa Scale (NOS) [43]. Study quality could explain some heterogeneity but not all. For example, NOS scores of all studies 
containing high-fat dairy or low-fat dairy were $\geq 7$, which could have resulted in lower heterogeneity for those analyses. Furthermore, residual confounding is a limitation of prospective cohort studies. The background diet should be taken into account in the statistical analyses as major confounders, which was done in 15 out of 29 cohort studies. Comparisons of dairy products with other foods in replacement models were not possible from the available data. The neutral risks of dairy products with mortality and CVD risk could be because of replacement by other foods, for example, those with high intake of dairy products may consume less sugar sweetened beverages which could lead to lower CVD mortality [66] or consume more processed meat which could lead to higher CVD risks $[67,68]$. For future studies it is important to investigate in more detail how dairy products can be replaced by other foods.

\section{Conclusions}

The current meta-analysis of 29 prospective cohort studies suggested neutral associations of total, high and low-fat dairy, milk and yogurt with risk of all-cause mortality, CHD and CVD. In addition, a possible role of fermented dairy was found in CVD prevention, but the result was driven by a single study.

Acknowledgements We are grateful to Professor Johanna M. Geleijnse for reviewing the paper and for suggestions and to Dr. Ágnes Fekete for her help with determining study quality using the NOS scoring system.

Funding This meta-analysis was partly funded by an unrestricted grant from the Global Dairy Platform, Dairy Research Institute and Dairy Australia. The Ph.D. scholarship of JG was supported by the Barham Benevolent Trust. The funders had no role in the study design, data collection, data analysis and results interpretation, writing of the report, or the decision to submit the article for publication.

Authors' contributions JG, AA, DIG, JAL, and SSSM designed the research. JG performed the literature search, extracted data. JG, SSSM checked data. JG performed the analyses and drafted the paper. AA, DIG, JAL, SSSM critically reviewed and improved it. JG is guarantor.

\section{Compliance with ethical standards}

Conflict of interest SSSM received funding from the Global Dairy Platform, Dairy Research Institute and Dairy Australia for a metaanalysis on cheese and blood lipids (2012) and this meta-analysis of dairy and mortality (2015). SSSM has also received the Wiebe Visser International Dairy Nutrition Prize from the Dutch Dairy Association's (NZO) Utrecht Group. AA is recipient of research grants from Arla Foods, DK; Danish Dairy Research Foundation; Global Dairy Platform; Danish Agriculture and Food Council; GEIE European Milk Forum, France. He is member of advisory boards for Dutch Beer Knowledge Institute, NL; IKEA, SV; Lucozade Ribena Suntory Ltd, UK; McCain Foods Limited, USA; McDonald's, USA; Weight Watchers, USA. He is consultant for Nestlé Research Center,
Switzerland; Nongfu Spring Water, China. Astrup receives honoraria as Associate Editor of American Journal of Clinical Nutrition, and for membership of the Editorial Boards of Annals of Nutrition and of Metabolism and Annual Review of Nutrition. He is recipient of travel expenses and/or modest honoraria $(<\$ 2000)$ for lectures given at meetings supported by corporate sponsors. He received financial support from dairy organizations for attendance at the Eurofed Lipids Congress (2014) in France and the meeting of The Federation of European Nutrition Societies (2015) in Germany; DIG and JG received funding from the Global Dairy Platform, DIG and JAL have received funding from The Dairy Council and AHDB Dairy for dietary pattern analysis of diets defined by dairy food content (2012-2015).

Open Access This article is distributed under the terms of the Creative Commons Attribution 4.0 International License (http://crea tivecommons.org/licenses/by/4.0/), which permits unrestricted use, distribution, and reproduction in any medium, provided you give appropriate credit to the original author(s) and the source, provide a link to the Creative Commons license, and indicate if changes were made.

\section{References}

1. Naghavi M, Wang H, Lozano R, Davis A, Liang X, Zhou M, Vollset SE, Ozgoren AA, Abdalla S, Abd-Allah F, et al. Global, regional, and national age-sex specific all-cause and causespecific mortality for 240 causes of death, 1990-2013: a systematic analysis for the Global Burden of Disease Study 2013. Lancet 2015; 385:117-71.

2. Mozaffarian D. Dietary and policy priorities for cardiovascular disease, diabetes, and obesity: a comprehensive review. Circulation. 2016;133:187-225.

3. Lamarche B, Givens DI, Soedamah-Muthu S, Krauss RM, Jakobsen MU, Bischoff-Ferrari HA, Pan A, Després JP. Does milk consumption contribute to cardiometabolic health and overall diet quality? Can J Cardiol. 2016;32:1026-32.

4. Alexander DD, Bylsma LC, Vargas AJ, Cohen SS, Doucette A, Mohamed M, Irvin SR, Miller PE, Watson H, Fryzek JP. Dairy consumption and CVD: a systematic review and meta-analysis. Br J Nutr. 2016;115:737-50.

5. Soedamah-Muthu SS, Ding EL, Al-Delaimy WK, Hu FB, Engberink MF, Willett WC, Geleijnse JM. Milk and dairy consumption and incidence of cardiovascular diseases and all-cause mortality: dose-response meta-analysis of prospective cohort studies. Am J Clin Nutr. 2011;93:158-71.

6. Michaelsson K, Wolk A, Langenskiold S, Basu S, Warensjo Lemming E, Melhus H, Byberg L. Milk intake and risk of mortality and fractures in women and men: cohort studies. BMJ. 2014;349:g6015.

7. Astrup A, Givens DI. Confusing message about dairy from Sweden. 2014. http://www.bmj.com/content/349/bmj.g6015/rr/ 790591. Accessed 31 Aug 2016.

8. Labos C, Brophy J. Statistical problems with study on milk intake and mortality and fractures. BMJ. 2014;349:g6991.

9. de Goede J, Soedamah-Muthu SS, Pan A, Gijsbers L, Geleijnse JM. Dairy consumption and risk of stroke: a systematic review and updated dose-response meta-analysis of prospective cohort studies. J Am Heart Assoc. 2016;5:e002787.

10. Pimpin L, Wu JH, Haskelberg H, Del Gobbo L, Mozaffarian D. Is butter back? A systematic review and meta-analysis of butter consumption and risk of cardiovascular disease, diabetes, and total mortality. PLoS ONE. 2016;11:e0158118. 
11. Stroup DF, Berlin JA, Morton SC, Olkin I, Williamson GD, Rennie D, Moher D, Becker BJ, Sipe TA, Thacker SB. Metaanalysis of observational studies in epidemiology: a proposal for reporting. JAMA. 2000;283:2008-12.

12. Kahn HA, Phillips RL, Snowdon DA, Choi W. Association between reported diet and all-cause mortality-21-year follow-up on 27,530 adult 7th-day adventists. Am J Epidemiol. 1984; 119:775-87.

13. Mann JI, Appleby PN, Key TJ, Thorogood M. Dietary determinants of ischaemic heart disease in health conscious individuals. Heart. 1997;78:450-5.

14. Appleby PN, Thorogood M, Mann JI, Key TJ. The Oxford Vegetarian Study: an overview. Am J Clin Nutr. 1999;70:525s$31 \mathrm{~s}$.

15. Bostick RM, Kushi LH, Wu Y, Meyer KA, Sellers TA, Folsom AR. Relation of calcium, vitamin D, and dairy food intake to ischemic heart disease mortality among postmenopausal women. Am J Epidemiol. 1999;149:151-61.

16. Hu FB, Stampfer MJ, Manson JE, Ascherio A, Colditz GA, Speizer FE, Hennekens CH, Willett WC. Dietary saturated fats and their food sources in relation to the risk of coronary heart disease in women. Am J Clin Nutr. 1999;70:1001-8.

17. Fortes C, Forastiere F, Farchi S, Rapiti E, Pastori G, Perucci CA. Diet and overall survival in a cohort of very elderly people. Epidemiology. 2000;11:440-5.

18. Ness AR, Smith GD, Hart C. Milk, coronary heart disease and mortality. J Epidemiol Commun Health. 2001;55:379-82.

19. Al-Delaimy WK, Rimm E, Willett WC, Stampfer MJ, Hu FB. A prospective study of calcium intake from diet and supplements and risk of ischemic heart disease among men. Am J Clin Nutr. 2003;77:814-8

20. Elwood PC, Pickering JE, Fehily AM, Hughes J, Ness AR. Milk drinking, ischaemic heart disease and ischaemic stroke I. Evidence from the Caerphilly cohort. Eur J Clin Nutr. 2004;58:711-7.

21. Knoops KT, de Groot LC, Fidanza F, Alberti-Fidanza A, Kromhout D, van Staveren WA. Comparison of three different dietary scores in relation to 10-year mortality in elderly European subjects: the HALE project. Eur J Clin Nutr. 2006;60:746-55.

22. Paganini-Hill A, Kawas CH, Corrada MM. Non-alcoholic beverage and caffeine consumption and mortality: the Leisure World Cohort Study. Prev Med. 2007;44:305-10.

23. Panagiotakos D, Pitsavos C, Chrysohoou C, Palliou K, Lentzas I, Skoumas I, Stefanadis C. Dietary patterns and 5-year incidence of cardiovascular disease: a multivariate analysis of the ATTICA study. Nutr Metab Cardiovasc Dis. 2009;19:253-63.

24. Bonthuis M, Hughes MC, Ibiebele TI, Green AC, van der Pols JC. Dairy consumption and patterns of mortality of Australian adults. Eur J Clin Nutr. 2010;64:569-77.

25. Goldbohm RA, Chorus AM, Galindo Garre F, Schouten LJ, van den Brandt PA. Dairy consumption and 10-y total and cardiovascular mortality: a prospective cohort study in the Netherlands. Am J Clin Nutr. 2011;93:615-27.

26. Sonestedt E, Wirfält E, Wallström P, Gullberg B, Orho-Melander M, Hedblad B. Dairy products and its association with incidence of cardiovascular disease: the Malmö diet and cancer cohort. Eur J Epidemiol. 2011;26:609-18.

27. Dalmeijer GW, Struijk EA, Van Der Schouw YT, SoedamahMuthu SS, Verschuren WMM, Boer JMA, Geleijnse JM, Beulens JWJ. Dairy intake and coronary heart disease or stroke-a population-based cohort study. Int J Cardiol. 2013;167:925-9.

28. Kondo I, Ojima T, Nakamura M, Hayasaka S, Hozawa A, Saitoh S, Ohnishi H, Akasaka H, Hayakawa T, Murakami Y, Okuda N, Miura K, Okayama A, Ueshima H. Consumption of dairy products and death from cardiovascular disease in the Japanese general population: the NIPPON DATA80. J Epidemiol. 2013;23:47-54.

29. Louie JC, Flood VM, Burlutsky G, Rangan AM, Gill TP, Mitchell P. Dairy consumption and the risk of 15-year cardiovascular disease mortality in a cohort of older Australians. Nutrients. 2013;5:441-54.

30. Patterson E, Larsson SC, Wolk A, Akesson A. Association between dairy food consumption and risk of myocardial infarction in women differs by type of dairy food. $J$ Nutr. 2013;143:74-9.

31. Soedamah-Muthu SS, Masset G, Verberne L, Geleijnse JM, Brunner EJ. Consumption of dairy products and associations with incident diabetes, CHD and mortality in the Whitehall II study. Br J Nutr. 2013;109:718-26.

32. van Aerde MA, Soedamah-Muthu SS, Geleijnse JM, Snijder MB, Nijpels G, Stehouwer CD, Dekker JM. Dairy intake in relation to cardiovascular disease mortality and all-cause mortality: the Hoorn Study. Eur J Nutr. 2013;52:609-16.

33. von Ruesten A, Feller S, Bergmann MM, Boeing H. Diet and risk of chronic diseases: results from the first 8 years of follow-up in the EPIC-Potsdam study. Eur J Clin Nutr. 2013;67:412-9.

34. Haring B, Gronroos N, Nettleton JA, Wyler Von Ballmoos MC, Selvin E, Alonso A. Dietary protein intake and coronary heart disease in a large community based cohort: results from the Atherosclerosis Risk in Communities (ARIC) study. PLoS ONE. 2014;9:e109552.

35. Huang LY, Wahlqvist ML, Huang YC, Lee MS. Optimal dairy intake is predicated on total, cardiovascular, and stroke mortalities in a Taiwanese cohort. J Am Coll Nutr. 2014;33:426-36.

36. Bergholdt HK, Nordestgaard BG, Varbo A. Ellervi k C. Milk intake is not associated with ischaemic heart disease in observational or Mendelian randomization analyses in 98,529 Danish adults. Int J Epidemiol. 2015;44:587-603.

37. Praagman J, Franco OH, Ikram MA, Soedamah-Muthu SS, Engberink MF, van Rooij FJ, Hofman A, Geleijnse JM. Dairy products and the risk of stroke and coronary heart disease: the Rotterdam Study. Eur J Nutr. 2015;54:981-90.

38. Praagman J, Dalmeijer GW, van der Schouw YT, SoedamahMuthu SS, Monique Verschuren WM, Bas Bueno-de-Mesquita H, Geleijnse JM, Beulens JW. The relationship between fermented food intake and mortality risk in the European Prospective Investigation into Cancer and Nutrition-Netherlands cohort. Br J Nutr. 2015;113:498-506.

39. Wang C, Yatsuya H, Tamakoshi K, Iso H, Tamakoshi A. Milk drinking and mortality: findings from the Japan collaborative cohort study. J Epidemiol. 2015;25:66-73.

40. Engberink MF, Soedaman-Muthu SS, Boessenkool-Pape J, van Rooij FJA, Hofman A, Witteman JCM, Geleijnse JM. Dairy intake in relation to all-cause mortality and risk of cardiovascular disease: the Rotterdam Study. American Heart Association, San Francisco. 2010 (poster 71).

41. Food Standards Agency. Food portion sizes. 3rd ed. Norwich: TSO; 2005.

42. United States Department of Agriculture. Food and nutrient database for dietary studies, 2006. http://www.ars.usda.gov/main/ site_main.htm?modecode=80-40-05-30. Accessed 31 Aug 2016.

43. Wells GASB, O'Connell D, Peterson J, Welch V, Losos M, Tugwell P. The Newcastle-Ottawa Scale (NOS) for assessing the quality of nonrandomised studies in meta-analyses. 2016. http:// www.ohri.ca/programs/clinical_epidemiology/oxford.asp. Accessed 31 Aug 2016.

44. Bauer SR, Hankinson SE, Bertone-Johnson ER, Ding EL. Plasma vitamin $\mathrm{D}$ levels, menopause, and risk of breast cancer: doseresponse meta-analysis of prospective studies. Medicine. 2013;92:123-31. 
45. Higgins JPT, Thompson SG. Quantifying heterogeneity in a meta-analysis. Stat Med. 2002;21:1539-58.

46. Egger M, Davey Smith G, Schneider M, Minder C. Bias in metaanalysis detected by a simple, graphical test. BMJ. 1997;315:629-34.

47. Larsson SC, Crippa A, Orsini N, Wolk A, Michaelsson K. Milk consumption and mortality from all causes, cardiovascular disease, and cancer: a systematic review and meta-analysis. Nutrients. 2015;7:7749-63.

48. Mullie P, Pizot C, Autier P. Daily milk consumption and allcause mortality, coronary heart disease and stroke: a systematic review and meta-analysis of observational cohort studies. BMC Public Health. 2016;1:1236.

49. Drouin-Chartier J-P, Brassard D, Tessier-Grenier M, Côté JA, Labonté M-È, Desroches S, Couture P, Lamarche B. Systematic review of the association between dairy product consumption and risk of cardiovascular-related clinical outcomes. Adv Nutr. 2016;7:1026-40.

50. Chen M, Li Y, Sun Q, Pan A, Manson JE, Rexrode KM, Willett WC, Rimm EB, Hu FB. Dairy fat and risk of cardiovascular disease in 3 cohorts of US adults. Am J Clin Nutr. 2016;104:1209-17.

51. NHS. Milk and dairy in your diet. 2015. http://www.nhs.uk/ Livewell/Goodfood/Pages/milk-dairy-foods.aspx. Accessed 31 Aug 2016.

52. Qin LQ, Xu JY, Han SF, Zhang ZL, Zhao YY, Szeto IM. Dairy consumption and risk of cardiovascular disease: an updated metaanalysis of prospective cohort studies. Asia Pac J Clin Nutr. 2015;24:90-100.

53. Drehmer M, Pereira MA, Schmidt MI, Alvim S, Lotufo PA, Luft VC, Duncan BB. Total and full-fat, but not low-fat, dairy product intakes are inversely associated with metabolic syndrome in adults. J Nutr. 2016;146:81-9.

54. Kratz M, Baars T, Guyenet S. The relationship between high-fat dairy consumption and obesity, cardiovascular, and metabolic disease. Eur J Nutr. 2013;52:1-24.

55. Larsson SC, Bergkvist L, Wolk A. High-fat dairy food and conjugated linoleic acid intakes in relation to colorectal cancer incidence in the Swedish Mammography Cohort. Am J Clin Nutr. 2005;82:894-900.

56. Beverley Bates AL, Chris Bates, Gillian Swan. National Diet and Nutrition Survey. 2012. https://www.gov.uk/government/ uploads/system/uploads/attachment_data/file/207708/NDNS-Y3report_All-TEXT-docs-combined.pdf. Accessed 31 Aug 2016.
57. Adebamowo SN, Spiegelman D, Flint AJ, Willett WC, Rexrode $\mathrm{KM}$. Intakes of magnesium, potassium, and calcium and the risk of stroke among men. Int J Stroke. 2015;10:1093-100.

58. Tian DY, Tian J, Shi CH, Song B, Wu J, Ji Y, Wang RH, Mao $\mathrm{CY}$, Sun SL, Xu YM. Calcium intake and the risk of stroke: an up-dated meta-analysis of prospective studies. Asia Pac J Clin Nutr. 2015;24:245-52.

59. Lorenzen JK, Jensen SK, Astrup A. Milk minerals modify the effect of fat intake on serum lipid profile: results from an animal and a human short-term study. Br J Nutr. 2014;111:1412-20.

60. Lorenzen JK, Astrup A. Dairy calcium intake modifies responsiveness of fat metabolism and blood lipids to a high-fat diet. Br J Nutr. 2011;105:1823-31.

61. Chen GC, Wang Y, Tong X, Szeto IM, Smit G, Li ZN, Qin LQ. Cheese consumption and risk of cardiovascular disease: a metaanalysis of prospective studies. Eur J Nutr. 2016. doi:10.1007/ s00394-016-1292-z.

62. Astrup A. Yogurt and dairy product consumption to prevent cardiometabolic diseases: epidemiologic and experimental studies. Am J Clin Nutr. 2014;99:1235S-42S.

63. Gijsbers L, Ding EL, Malik VS, de Goede J, Geleijnse JM, Soedamah-Muthu SS. Consumption of dairy foods and diabetes incidence: a dose-response meta-analysis of observational studies. Am J Clin Nutr. 2016;103:1111-24.

64. Veiga P, Pons N, Agrawal A, Oozeer R, Faurie JM, van Hylckama Vlieg JE, Houghton LA, Whorwell PJ, Ehrlich SD, Kennedy SP. Changes of the human gut microbiome induced by a fermented milk product. Sci Rep. 2014;4:6328.

65. van Hylckama Vlieg JE, Veiga P, Zhang C, Derrien M, Zhao L. Impact of microbial transformation of food on health-from fermented foods to fermentation in the gastro-intestinal tract. Curr Opin Biotechnol. 2011;22:211-9.

66. Yang QH, Zhang ZF, Gregg EW, Flanders WD, Merritt R, Hu FB. Added sugar intake and cardiovascular diseases mortality among US adults. JAMA Intern Med. 2014;174:516-24.

67. Micha R, Wallace SK, Mozaffarian D. Red and processed meat consumption and risk of incident coronary heart disease, stroke, and diabetes mellitus. A systematic review and meta-analysis. Circulation. 2010;121:2271-83.

68. Chen GC, Lv DB, Pang Z, Liu QF. Red and processed meat consumption and risk of stroke: a meta-analysis of prospective cohort studies. Eur J Clin Nutr. 2013;67:91-5. 